\title{
THE RELATIONSHIP BETWEEN SECOND-TO-FOURTH DIGIT RATIO (2D:4D), MUSCLE STRENGTH AND BODY COMPOSITION TO BONE MINERAL DENSITY IN YOUNG WOMEN
}

\author{
Hamid Arazi and Ehsan Eghbali \\ Department of Exercise Physiology, Faculty of Sport Sciences, University of Guilan, Rasht, Iran
}

Original scientific paper

DOI: $10.26582 / \mathrm{k} .51 .2 .8$

\begin{abstract}
:
2D:4D ratio is determined by the balance between androgens and estrogens. Low level estrogen reduces bone mineral density (BMD) and incurs negative changes to bone microarchitecture, increasing the risk of osteoporosis and, as a consequence, fracture risk in women. The purpose of this study was to investigate the relationship between 2D:4D, muscle strength and body composition to BMD in young women. One hundred twenty-seven young women (age range 24-36 years) voluntarily participated in this study. Lengths of the second (index) and fourth (ring) fingers, upper and lower body strength and body composition (body mass index, BMI; waist to hip ratio, WHR) and body fat percentage were estimated. Also, blood levels of calcium and 25-hydroxyvitamin D (25OHD) were evaluated and dual-energy X-ray absorptiometry device was used to measure BMD in the lumbar spine (LS) and femoral neck (FN). The results showed that digit ratios, upper body and lower body muscle strength, BMI and fat percentage had a positive relationship with LS and FN BMD (LS BMD: $r=.47, r=.56, r=.46, r=.34, r=.28, p \leq .001$, respectively; FN BMD: $r=.34, r=.49$, $\mathrm{r}=.51, \mathrm{r}=.45, \mathrm{r}=.27, \mathrm{p} \leq .001$, respectively). In addition, there was no significant relationship between WHR and BMD of LS and FN ( $>$ >.05). Multiple linear regression analysis showed the upper body strength was a stronger determinant of LS BMD and the lower body strength was a stronger determinant of FN BMD. Based on the results, the researchers concluded that upper and lower body strength, 2D:4D ratios and BMI were important determinants of young women's BMD. Also, it seemed that some of these factors may be able to help predicting the osteoporosis potential in young women.
\end{abstract}

Key words: osteoporosis, 2D:4D, chest press, leg press, fat percentage

\section{Introduction}

Osteoporosis is one of the main and widespread health problems in the world that incurs high death rate and costs for patients (Miller, et al., 2009). Among the factors causing osteoporosis are gender, age, body size, ethnicity, family history, hormonal levels, eating disorders, calcium and vitamin D intake, medication use, smoking, alcohol consumption and physical activity (National Institutes of Health, 2015). Bone mineral density (BMD) is largely determined by genetics, but an important factor determining bone mass in adolescents is the anabolic effect of increased levels of growth hormone and steroids. These factors can have some impacts on the bone by circulation and peak bone mass (PBM). Moreover, optimal nutrition is very important to maintain proper energy balance, optimizing bone growth and skeletal development (Nasri, Hassen Zrour, \& Rebai, 2013).
A lot of research has been done on the 2D:4D ratio in humans. The ratio of fingers, especially the second to the fourth, is determined and formed in the fetal period, and then remains the same during the growth period of an individual. After nine weeks of pregnancy, the fetus grows rapidly, and that period becomes highly sensitive for the fetus (Lu, Ma, Zhao, \& Huo, 2015). So, during that period, if there are changes in the environment of the uterus (such as malnutrition or changes in the level of hormone within the uterus), not only will systems and organs structure of the fetus change, but also it affects ratio of fingers. Therefore, studying the ratio of fingers can indirectly indicate development of embryo during the fetal period in the uterus and the changes occurring in this period (Lu, et al., 2015; Yamamoto, Tamura, Ono, Takei, \& Sano, 2015).

Over the past decade, research has been conducted on the $2 \mathrm{D}: 4 \mathrm{D}$ ratio in different soci- 
eties, and there correlations have been established between fetal sex steroids, general health and physical fitness of a person (Honekopp, Bartholdt, Beier, \& Liebert, 2007; Lu, et al., 2015). It has recently been suggested that the 2D:4D ratio is negatively associated with the fetal testosterone and positively related to embryoid estrogen. Also, according to what was mentioned above, it is argued that high fetal testosterone and low estrogen (decreasing the 2D:4D ratio) favor the male fetus, and low fetal testosterone and high estrogen (increased 2D:4D ratio) favor the female fetus (Manning, et al., 2000). Accordingly, the ratio of 2D:4D in men is lower than in women. The difference in this ratio is controlled by the Homeobox or Hox gene (Hox and Hoxa gene) (Manning, et al., 2000) and remains constant in life; it is not even affected by the onset of puberty (Trivers, Manning, \& Jacobson, 2006). Furthermore, genetic studies have shown that Runx2, Sox9, lgfbp2/5, Fgfr2, Bmp6, Ihh and Wnt5a play an important role in the development of fingers and other bone proportions (Zheng \& Cohn, 2011).

In recent years, several studies have examined the relationship between fingers and certain diseases (such as osteoarthritis, coronary artery disease, breast cancer, etc.) in women. Some evidence suggested that the prenatal balance of sex hormones, reflected in the 2D:4D ratio, might have a multilateral long-term effect on the human biological condition affecting adult disease risk, especially those sex steroids related diseases (Klimek, Galbarczyk, Nenko, \& Jasienska, 2016; Wang, et al., 2018; Lu, et al., 2015).

Bone and muscle are active metabolic tissues continuously regulated with harmony of counteracting processes. They are multifactorial and pathophysiological pathways share different (Boirie, 2009). Previous studies showed that the reduction of serum estrogens, IGF1, increased levels of proinflammatory cytokines (IL-6, TNF- $\alpha$ ) and possible changes of genes in common (reduction of AKT) was related to type II muscle fiber atrophy (Tagliaferri, Wittrant, Davicco, Walrand, \& Coxam, 2015). The results of several studies showed that there was a direct relationship of strength and body mass with BMD. Arazi, Eghbali, Saeedi, and Moghadam (2016) showed that muscle strength was positively related to BMD in postmenopausal women. In addition, Khalil, Faulkner, Greenspan, and Cauley (2014) demonstrated that there was no significant relationship between strength and BMD.

Body composition refers to the amount and distribution of fat mass and fat-free mass (Saarelainen, et al., 2012). Body composition (lean and fat mass) is closely related to BMD values in postmenopausal women (Saarelainen, et al., 2012). Body mass index (BMI) is a simple and easy index of weight for height that is commonly used to classify underweight, overweight, and obese persons.
The relationship between BMI and fracture risk is non-linear (Compston, et al., 2014). Various studies indicated that BMI is inversely associated with the risk of osteoporotic hip fracture, while its relationship with other limb fractures is still debated among authors (Gnudi, Sitta, \& Lisi, 2009). Also, various studies indicated no relationship between BMI and BMD (Babaroutsi, Magkos, Manios, \& Sidossis, 2005; Sarkis, Martini, Szejnfeld, \& Pinheiro, 2012). Opposite to that, Moon (2014) demonstrated that BMI was positively correlated with femoral neck (FN) and lumbar spine (LS) BMD.

According to the stated, it seems that the 2D:4D ratio, body composition, and muscle strength are likely to be related to BMD through common genes with bone, their relationship with estrogen and testosterone, and generally pathophysiological pathways. Moreover, the relationship between the 2D:4D ratio and BMD in young women has not been studied; so, the researchers decided to study this topic for the first time. Also, according to the effects of some ethnic, environmental factors and differences in lifestyle (such as mobility, nutrition and its effects on BMD) and the lack of studies on the relationship between these variables and BMD in Iranian women, there is a need to examine possible associations between them.

\section{Methods}

\section{Participants}

A descriptive study included 127 women (age range 24-36 years). The participants in this study were selected among 382 volunters who declared their willingness on a voluntary basis, after announcements in medical offices and associated laboratories. The researchers excluded those participants who suffered from the established rheumatologic diseases; had a history of taking drugs affecting BMD (corticosteroids), parathyroids and adrenal glands; had diabetes and advanced liver failure; had advanced heart disease or any type of cancer; sustained fractures in the previous months; had any implant in the body; completed bed rest for three consecutive months; or those who were smoking and consumed alcohol. Also, the participants in this study were not pregnant and did not take hormonal contraceptives in the last six months (El Hage, et al., 2014; Sherk, Palmer, Bemben, \& Bemben, 2009; Marin, Pedrosa, MoreiraPfrimer, Matsudo, \& Lazaretti-Castro, 2010). The researchers described the research process and procedures to the participants and asked them to fill out the consent form and general health questionnaire. The work described has been carried out in accordance with the Declaration of Helsinki. All the steps were verified by the University's ehtical committee. 


\section{Measurement of body composition}

In this study, body composition includes: BMI, waist to hip ratio (WHR), and fat percentage. After the body height and body weight measuring, BMI was calculated by dividing body weight $(\mathrm{kg})$ by body height (m) squared. Also, to measure WHR, the waist circumference was divided by the hip circumference. The researcher used Jackson and Pollock's method to measure body fat percentage. Subcutaneous fat thickness at three sites of the body, including the triceps, supraspinale and thigh, was measured and the body density was determined for each individual (Jackson \& Pollock, 1978). Then, using Brozek equation, body fat percentage was calculated for each individual (Brozek, Grande, Anderson, \& Keys, 1963). Skin-fold thickness was obtained using calipers (Lafayette model o1127, USA) calibrated to $1 \mathrm{~mm}$ accuracy. All the measurement was done on the right side of the body three times and the average was used for further analysis.

\section{Fingers ratio measurement}

A digital scanner (model 5590 HP Scanjet, American) was used to measure fingers. The participants put the palm of their hands on the scanner, stayed in front of it and kept a two-centimeter distance between finger tips (right hand). The image was sent to the computer and the researchers used Kinovea software to measure fingers' length with the accuracy of $0.01 \mathrm{~cm}$. The fingers' length was measured from basal crease proximal to the palm to the tip of the finger. The second to fourth finger length by the ratio was measured by dividing the index finger ring finger length (Manning, Scutt, Wilson, \& Lewis-Jones, 1998).

\section{Measurement of upper and lower body strength}

To measure upper body strength, the researchers used the chest press test and for lower body strength, they used the leg press test. The amount of weight and the number of repetitions were recorded for each individual and the maximum repetition was obtained using Brzycki formula (Brzycki, 1993).

One-repetition maximum $(1 \mathrm{RM})=$ Load $(\mathrm{kg})$

$\overline{1.0278-[0.0278 \times \text { maximum number of repetitions] }}$

\section{Blood measurements}

Blood levels measurement sampling (25OHD and calcium) was done while the participants were fasting (8:00 to 10:00 a.m.). The subjects donated five cc blood from their brachial vein. Then, the blood was transferred to the laboratory and centrifuged at $3000 \mathrm{rpm}$ and the calcium and 25OHD values were determined. The determination of
25OHD was tested by enzyme-linked immunosorbent assay method with sensitivity of five $\mathrm{nm} / \mathrm{L}$ (Stat Fax 2100, Awareness Technology, Palm City, FL). The blood level of calcium was determined with the Auto Analyzer RA-100 (Bayer-Technicon, Leverkusen, Germany). The normal levels of 25OHD above $20 \mathrm{ng} / \mathrm{ml}$ and calcium 8.50-10.50 $\mathrm{mg} / \mathrm{dl}$ were considered (IOM, 2011).

\section{Measurement of BMD}

BMD in the LS and FN was measured using dual-energy X-ray absorptiometry device (QDR $4500 \mathrm{~W}$, Hologic Inc., Bedford, MA) and the results were recorded as T-score. In this analysis, BMD at the LS was estimated from L2 to L4. The FN BMD used in the analysis was estimated on the right side. We divided the sample into three groups using the World Health Organization (WHO) classification of healthy, osteopenic and osteoporotic persons. The WHO defines osteopenia and osteoporosis based on BMD: osteopenia is BMD less than -1 and more than -2.5 standard deviations in relation to the mean BMD of young adults, and osteoporosis is BMD less than -2.5 standard deviations in relation to the mean BMD of young adults (WHO Scientific Group, 2003).

\section{Statistical analysis}

Mean and standard deviations of data were calculated using descriptive statistics. The researchers used Kolmogorov-Smirnov test to check for the normality of data. Associations between the variables were given as Pearson's correlation coefficients and $r$ values were reported. Multiple linear regression analysis models were used to test the relationship between variables, and $\mathrm{R}^{2}$ values were reported. To compare the results between the groups of healthy, osteopenic and osteoporotic participants, one-way analysis of variance (ANOVA) was used. Bonferroni post-hoc test was used for multiple comparisons. The analyses were performed using SPSS 22 and Excel 2016. The $\mathrm{p} \leq .05$ was considered as the level of significance.

\section{Results}

Table 1 shows characteristics of the participants. Regarding muscle strength, the results showed that there was a significant relationship between the upper body muscle strengths and the LS and FN BMD $(r=.56, r=.49, p<.001)$. Also, there was a significant relationship between the lower body muscle strengths and the LS and FN BMD ( $\mathrm{r}=.46$, $\mathrm{r}=.51, \mathrm{p}<.001$ ) (see Table 2). Moreover, the results of this study showed that there was a positive and significant relationship between 2D:4D ratio and BMD in both areas $(r=.47, r=.34, p<.001$; respectively for LS and FN). Also, there was a positive relationship between BMI and fat percentage and 
Table 1. Characteristics of study subjects

\begin{tabular}{lc}
\hline Characteristic & M \pm SD \\
\hline Age (years) & $31.33 \pm 4.28$ \\
Body height $(\mathrm{cm})$ & $158.74 \pm 5.87$ \\
Body weight $(\mathrm{kg})$ & $59.32 \pm 4.83$ \\
WHR & $0.74 \pm 0.06$ \\
BMl $\left(\mathrm{kg} / \mathrm{m}^{2}\right)$ & $23.94 \pm 4.98$ \\
Fat $(\%)$ & $34.81 \pm 4.78$ \\
2D:4D & $0.97 \pm 0.08$ \\
Chest press (kg) & $20.31 \pm 6.19$ \\
Leg press (kg) & $56.79 \pm 18.39$ \\
Calcium (mg/dl) & $8.79 \pm 0.36$ \\
25OHD (ng/ml) & $42.37 \pm 17.22$ \\
LS (L2-L4) BMD (T-score) & $0.27 \pm 0.90$ \\
FN BMD (T-score) & $-0.79 \pm 0.80$ \\
\hline
\end{tabular}

Note. Waist to hip ratio (WHR); body mass index (BMI); 25-hydro-xyvitamin D (25OHD); lumbar spine (LS); bone mineral density (BMD); femoral neck (FN). the LS and FN BMD (BMI: $\mathrm{r}=.34, \mathrm{r}=.45, \mathrm{p}<.001$; fat percentage: $\mathrm{r}=.28, \mathrm{r}=.27, \mathrm{p}=.001$; respectively). Opposite to that, there was no relationship between WHR and the LS and FN BMD $(r=-.09, p=.30$, $\mathrm{r}=.10, \mathrm{p}=.26$; respectively) (see Table 2).

Table 2. Associations between strength, 2D:4D ratio, BMI, WHR and fat percent with BMD (T-score)

\begin{tabular}{lcccc}
\hline \multirow{2}{*}{ Variable } & \multicolumn{2}{c}{ LS BMD } & \multicolumn{2}{c}{ FN BMD } \\
\cline { 2 - 5 } & $\mathbf{r}$ & $\mathbf{p}$ & $\mathbf{r}$ & $\mathbf{p}$ \\
\hline BMI $\left(\mathrm{kg} / \mathrm{m}^{2}\right)$ & .34 & $<.001^{*}$ & .45 & $<.001^{*}$ \\
WHR & -.09 & .30 & .10 & .26 \\
Fat $(\%)$ & .28 & $.001^{*}$ & .27 & $.001^{*}$ \\
2D:4D & .47 & $<.001^{*}$ & .34 & $<.001^{*}$ \\
Chest press $(\mathrm{kg})$ & .56 & $<.001^{*}$ & .49 & $<.001^{*}$ \\
Leg press $(\mathrm{kg})$ & .46 & $<.001^{*}$ & .51 & $<.001^{*}$ \\
\hline
\end{tabular}

Note. Lumbar spine (LS); bone mineral density (BMD); femoral neck (FN): waist to hip ratio (WHR); body mass index (BMI). *Significance at the $\leq .05$ level.

Table 3. Multiple linear regression analysis models

\begin{tabular}{|c|c|c|c|c|}
\hline Variables & B & $\beta$ & SE & p \\
\hline \multicolumn{5}{|c|}{ Dependent variable: TS LS $\left(R^{2}=.42\right.$, Durbin-Watson $\left.=1.41\right)$} \\
\hline Chest press $(\mathrm{kg})$ & .055 & .377 & .012 & $<.001$ \\
\hline 2D:4D & 2.77 & .250 & .868 & .002 \\
\hline Leg press $(\mathrm{kg})$ & .009 & .192 & .004 & .01 \\
\hline \multicolumn{5}{|c|}{ Dependent variable: TS FN $\left(\mathrm{R}^{2}=.40\right.$, Durbin-Watson $\left.=1.40\right)$} \\
\hline Leg press (kg) & .015 & .334 & .003 & $<.001$ \\
\hline BMI $\left(\mathrm{kg} / \mathrm{m}^{2}\right)$ & .042 & .263 & .012 & .001 \\
\hline Chest press (kg) & .030 & .235 & .011 & .005 \\
\hline
\end{tabular}

Note. Unstandardized regression coefficient (B); standardized regression coefficient ( $\beta$ ); standard error (SE): T-score (TS); lumbar spine (LS); femoral neck (FN); body mass index (BMI).

Table 4. Strength, 2D:4D ratio, BMI, WHR and fat percent in women with healthy, osteopenic and osteoporotic LS and FN according to the WHO classification

\begin{tabular}{|c|c|c|c|c|}
\hline \multirow[b]{2}{*}{ Variable } & \multicolumn{2}{|c|}{ LS BMD } & \multicolumn{2}{|c|}{ FN BMD } \\
\hline & Healthy (64) & $\begin{array}{l}\text { vs. osteopenic (39) } \\
\text { vs. osteoporotic (24) }\end{array}$ & Healthy (39) & $\begin{array}{l}\text { vs. osteopenic ( } 56) \\
\text { vs. osteoporotic ( } 32)\end{array}$ \\
\hline 2D:4D & 0.99 & $\begin{array}{l}\text { vs. } 0.95(p=.05) \\
\text { vs. } 0.89(p<.001)\end{array}$ & 0.98 & $\begin{array}{l}\text { vs. } 0.96(p=.78) \\
\text { vs. } 0.92(p=.003)\end{array}$ \\
\hline Chest press (kg) & 22.97 & $\begin{array}{l}\text { vs. } 19.25(p=.003) \\
\text { vs. } 14.96(p<.001)\end{array}$ & 22.58 & $\begin{array}{l}\text { vs. } 20.35(p=.22) \\
\text { vs. } 17.48(p=.001)\end{array}$ \\
\hline Leg press (kg) & 61.53 & $\begin{array}{l}\text { vs. } 55.49(p=.28) \\
\text { vs. } 46.28(p<.001)\end{array}$ & 63.99 & $\begin{array}{l}\text { vs. } 57.93(p=.28) \\
\text { vs. } 46.02(p<.001)\end{array}$ \\
\hline BMI $\left(k g / m^{2}\right)$ & 25.20 & $\begin{array}{l}\text { vs. } 24.00(p=.63) \\
\text { vs. } 20.50(p<.001)\end{array}$ & 25.30 & $\begin{array}{l}\text { vs. } 23.88(p=.49) \\
\text { vs. } 22.41(p=.04)\end{array}$ \\
\hline WHR & 0.74 & $\begin{array}{l}\text { vs. } 0.74(p=1.00) \\
\text { vs. } 0.73(p=1.00)\end{array}$ & 22.58 & $\begin{array}{l}\text { vs. } 20.35(p=1.00) \\
\text { vs. } 17.48(p=.53)\end{array}$ \\
\hline Fat (\%) & 35.85 & $\begin{array}{l}\text { vs. } 35.19(p=1.00) \\
\text { vs. } 31.44(p<.001)\end{array}$ & 35.62 & $\begin{array}{l}\text { vs. } 35.27(p=1.00) \\
\text { vs. } 33.03(p=.06)\end{array}$ \\
\hline
\end{tabular}

Note: Lumbar spine (LS); bone mineral density (BMD); femoral neck (FN): waist to hip ratio (WHR); body mass index (BMI). 
The results of the stepwise multiple linear regression analysis models are shown in Table 3. Chest press was a strong predictor of LS BMD $(\beta=.377, \mathrm{p}<.001)$ and leg press was a strong predictor of FN BMD $(\beta=.334, \mathrm{p}<.001)$ (see Table 3$)$.

The subjects were divided into healthy, osteopenic and osteoporotic groups according to their T-scores of the LS and FN BMD (WHO classification). Osteoporotic women, according to LS and FN BMD, performed significantly worse in body strength $(\mathrm{p}<.05)$ (see Table 4). According to LS BMD, 2D:4D, BMI and fat percent were significantly lower in osteoporotic women compared to healthy women $(\mathrm{p}<.05)$. Also, osteoporotic women, according to FN BMD, had a significantly lower 2D:4D and BMI compared to healthy women $(\mathrm{p}<.05)$ (see Table 4).

\section{Discussion and conclusion}

Our results showed that there was a significant relationship between digit ratios, upper body and lower body muscle strength, BMI and fat percentage to LS and FN BMD. The main findings of this study indicated that chest press was a strong predictor of LS BMD and leg press was a strong predictor of FN BMD in young women.

Estrogen is a regulator of bone metabolism in men and women. Khosla, Oursler, and Monroe (2012) suggested the effects of estrogen regulation on bone turnover by the impact on osteocytes, osteoblasts and T-cells. Estrogen directly affects osteocytes, osteoblasts and osteoclasts and acts as an inhibitor of osteoclasts blocking their activation directly or through osteoblasts and T-cells. Ultimately, the estrogen action on the skeleton is reduced by remodeling, bone resorption and maintaining bone formation (Cauley, 2015; Khosla, et al., 2012).

The results of this study indicated a significant relationship between 2D:4D and BMD. Androgen and estrogen receptors have more activity on the fourth finger than the second finger. The inactivation of the androgen receptor reduces the growth of the fourth finger and increases the 2D:4D ratio, while the inactivation of the estrogen receptor increases growth of the fourth finger and reduces the 2D:4D ratio. Androgens and estrogens separately regulate the chondrocyte proliferation controlling genes that results in the separate growth of fourth finger in men and women. These studies identified molecular dimorphisms between men and women's limb, and empirical evidence also showed that fingers had a lifelong relationship to prednisolone hormones (prenatal hormonal exposure). This shows how to maintain this ratio among mammals (Zheng \& Cohn, 2011; Li, et al., 2016). In addition, as stated, this ratio remains constant over a lifetime and is not affected by the onset of puberty (Trivers, et al., 2006). As mentioned, the difference in 2D:4D is controlled by the Homeobox or Hox gene (Hox and Hoxa gene) (Manning, et al., 2000). Hox genes is an important regulator of the musculoskeletal system (muscle, tendon and bone) and plays an important role in skeletal patterning through axial and appendicular skeletons (Pineault \& Wellik, 2014).

The $2 \mathrm{D}$ to $4 \mathrm{D}$ ratio transcript levels are determined by 19 genes. Several genes are set in skeleton and other tissues by steroids; genetic studies have shown that Sox9, lgfbp2/5, Fgfr2, Bmp6, Ihh, and Wnt5a play important roles in the development of 2D:4D ratio (Zheng \& Cohn, 2011). For example, it has been shown that Wnt5a adjusts the rate of chondrocyte and puberty in long bones. The findings indicated that androgen was a negative expression regulator of Wnt5a in the ratio of fingers; when Wnt5a is positively regulated on the fourth finger after contrasting with androgen, cell proliferation may decrease in this case, and size of the fourth fingers may be shortened and the ratio of the second to the fourth fingers increases, and thus, leads to the development of an increase in the ratio of femininity in the fingers (Zheng \& Cohn, 2011).

Many factors, including Ihh, parathyroid hormone-related protein (PTHrP), Bmps, and Fgfs affect way and speed of chondrocytes transmission from the resting-immature to the hypertrophic state and ultimately causing formation of the bone collar (Karsenty, Kronenberg, \& Settembre, 2009; Kobayashi \& Kronenberg, 2014). Ihh is a key regulator for the development of long bones that modulates cartilage growth and osteoblastogenesis. Furthermore, it regulates the rate of maturity of the chondrocyte by activating PTHrP at the joint surface. Ihh is also required for the propagation of chondrocyte and osteoblast differentiation that acts through independent pathways of PTHrP. Moreover, Runx 2 also plays a role in bone formation (González-Martín, Mallo, \& Ros, 2014; Long, et al., 2004).

A very few studies have investigated the relationship between bone density and fingers' ratio. In this regard, there is a study conducted by Arazi et al. (2016) which showed a positive relationship between 2D:4D ratio and BMD in postmenopausal women. These results are in line with the results of our study.

Regarding muscle strength, the results showed a positive relationship between strength and BMD. In line with the results of the present study, the results of Kärkkäinen et al. (2008) showed that handgrip strength and leg extension strength were related to BMD in postmenopausal women. Also, Arazi et al. (2016) showed that muscle strength was positively related to BMD in postmenopausal women. Sherk et al. (2009) found a relationship between muscle strength and BMD in specific areas and showed that lower body muscle strength and muscle mass had strong effects on BMD in femur bone. Women 
suffering from sarcopenia had more symptoms of osteopenia in the total body, LS and forearm BMD sites. In their study, they found a significant relationship between upper body muscle strength and femur BMD (Sherk, et al., 2009). Opposite to the results of the present study, Khalil et al. (2014) demonstrated that there was no significant relationship of handgrip strength and leg extension strength to BMD in the old men; it seems that these results may be due to differences in gender. The researchers argued that environmental factors are strongly effective in muscle strength.

Many paths are involved in the relationship between muscle strength and BMD. However, all effective paths are not fully understood. One of these mechanisms includes osteocalcin, an osteoblast-derived protein marker of bone formation that stimulates $\beta$-cell proliferation and insulin secretion and acts directly on skeletal muscle, correlating with muscle strength (Hirschfeld, Kinsella, \& Duque, 2017). Another intrinsic mechanism of muscle and bone involvement is the secretion of vascular endothelial growth factor (VEGF) by bone marrow mesenchymal stromal cell stimulating the proliferation of myoblast. The muscle also secretes several endocrine molecules affecting the bone, such as IGF-1, irisin, osteonectin, osteoglycine, fibroblast growth factor-2 (FGF2), IL-6, IL-5, myostatin and matrix metalloproteinase 2 (MMP2) (Hirschfeld, et al., 2017; Tagliaferri, et al., 2015). Furthermore, hormonal factors found in the bone (FGF21, subcaboxylated osteocalcin, and sclerostin) have some effects on skeletal muscle. There are also common pathways such as GH/IGF-1, sex steroids, and Wnt signaling in the bone-muscle control unit which can be compatible with mechanical stimulation and damage (Lebrasseur, Achenbach, Melton, Amin, \& Khosla, 2012).

The results of the present study showed a significant and positive relationship between BMI and fat percentage, on the one hand, and BMD. In this regard, El Hage, Theunynck, and Jacob (2012a) showed that there was a positive relationship of BMI and fat with BMD in the LS, trochanteric and FN in women. The results of the study by El Hage and Baddoura (2012b) with postmenopausal women showed that body weight, BMI, fat mass and fat percentage had a positive and significant relationship with BMD FN CSA (cross-sectional area), FN Z (section modulus), IT (intertrochanteric) CSA, IT Z, FS (femoral shaft) CSA, FS Z. Also, Xiang et al. (2017) showed that fat mass independently influenced the BMD of Chinese postmenopausal women. Johansson et al. (2014) indicate that, compared to BMI of $25 \mathrm{~kg} / \mathrm{m}^{2}$, the hazard ratio for osteoporotic fracture was a BMI of $35 \mathrm{~kg} / \mathrm{m}^{2}$. Opposite to that, some studies indicated no relationship between BMI and BMD (Babaroutsi, et al., 2005; Sarkis, et al., 2012).
Some interacting mechanisms between fat and bone may include the relationship between fat mass and secretion of bone activating hormones from the pancreatic beta cells (insulin, amylin, and preptin), bone-active hormones (estrogens and leptin) from adipocytes and the load of soft tissue on the skeleton (Reid, 2008). Increased body weight and fat mass are associated with decrease in free testosterone in men and increase in estrogen in women (El Hage, et al., 2012a). On the other hand, fatness is associated with increase in environmental estrogen. These changes may be due to the increased synthesis of osteoblast and decreased osteoclast activity (Genaro, Pereira, Pinheiro, Szejnfeld, \& Martini, 2010). However, the relationship between fat mass and bone density is dependent on gender, diet, genetics and physical activity and the procedure of body composition measuring (Genaro, et al., 2010).

The evidence has shown that increased WHR is related to hormonal factors (high levels of androgen and cortisol, low levels of estrogen) and may lead to success in sporting activities, especially in difficult and stressing situations (Cashdan, 2008). Manning et al. (2000) showed that the women with low levels of WHR had lower testosterone and higher estrogen, while the women with higher WHR had higher testosterone and lower estrogen. Based on these results and the relationship between bone density and estrogen levels in women, it seems that WHR has a negative relationship with BMD; however, our results did not show a significant relationship between WHR and BMD. A few studies have investigated this issue; the results of Arazi et al. (2016) showed a negative relationship between WHR and BMD in postmenopausal women. Also, Li, Gong, and Jiang (2017) suggested that WHR might be associated with an increased risk of hip fracture, and the hip fracture risk could be increased substantially when the waist circumference is $\geq 100 \mathrm{~cm}$.

It seems that this controversy may be due to stress level, type of activity and individuals' responsibility in the society. The research has shown that the women exposed to a higher level of stress experience higher levels of WHR independent of BMI. Stress leads to increase in cortisol, which, in turn, leads to increase in WHR (Cashdan, 2008). In societies where individuals are socially and economically independent, the WHR ratio may be different (Cashdan, 2008). So, it seems that the WHR ratio is dependent on different variables.

The results of this study showed that the 2D:4D ratio, muscle strength, and BMI are fair determinants and play important roles in young women's BMD. Moreover, it seems that the use of some of these variables may help to preventing osteoporosis in women. However, the researchers suggested that there is a need for more studies in this area to find more acceptable and comprehensive results. 


\section{References}

Arazi, H., Eghbali, E., Saeedi, T., \& Moghadam, R. (2016). The relationship of physical activity and anthropometric and physiological characteristics to bone mineral density in postmenopausal women. Journal of Clinical Densitometry, 19(3), 382-388.

Babaroutsi, E., Magkos, F., Manios, Y., \& Sidossis, L.S. (2005). Body mass index, calcium intake, and physical activity affect calcaneal ultrasound in healthy Greek males in an age-dependent and parameter-specific manner. Journal of Bone and Mineral Metabolism, 23(2), 157-166.

Boirie, Y. (2009). Physiopathological mechanism of sarcopenia. Journal of Nutrition Health and Aging, 13(8), $717-723$.

Brozek, J., Grande, F., Anderson, J.T., \& Keys, A. (1963). Densitometric analysis of body composition: Revision of some quantitative assumptions. Annals of the New York Academy of Science, 110, 113-140.

Brzycki, M. (1993). Strength testing - Predicting a one-rep max from reps-to-fatigue. Journal of Physical Education, Recreation and Dance, 64(1), 88-90.

Cashdan, E. (2008). Waist-to-hip ratio across cultures: Trade-offs between androgen-and estrogen-dependent traits. Current Anthropology, 49(6), 1099-1107.

Cauley, J.A. (2015). Estrogen and bone health in men and women. Steroids, 99, 11-15.

Compston, J.E., Flahive, J., Hosmer, D.W., Watts, N.B., Siris, E.S., Silverman, S., \& Adachi, J.D. (2014). Relationship of weight, height, and body mass index with fracture risk at different sites in postmenopausal women: The global longitudinal study of osteoporosis in women (GLOW). Journal of Bone and Mineral Research, 29(2), 487-493.

El Hage, R., \& Baddoura, R. (2012b). Anthropometric predictors of geometric indices of hip bone strength in a group of Lebanese postmenopausal women. Journal of Clinical Densitometry, 15(2), 191-197.

El Hage, R., Theunynck, D., \& Jacob, C. (2012a). Anthropometric predictors of bone mineral density in healthy Lebanese subjects aged 13 to 25 years. Science and Sports, 27(4), 241-245.

El Hage, R., Zakhem, E., Theunynck, D., Zunquin, G., Bedran, F., Sebaaly, A., \& Maalouf, G. (2014). Maximal oxygen consumption and bone mineral density in a group of young Lebanese adults. Journal of Clinical Densitometry, $17(2), 320-324$.

Genaro, P.S., Pereira, G.A., Pinheiro, M.M., Szejnfeld, V.L., \& Martini, L.A. (2010). Influence of body composition on bone mass in postmenopausal osteoporotic women. Archives of Gerontology and Geriatrics, 51(3), $295-298$.

Gnudi, S., Sitta, E., \& Lisi, L. (2009). Relationship of body mass index with main limb fragility fractures in postmenopausal women. Journal of Bone and Mineral Metabolism, 27(4), 479-484.

González-Martín, M.C., Mallo, M., \& Ros, M.A. (2014). Long bone development requires a threshold of Hox function. Developmental Biology, 392(2), 454-465.

Hirschfeld, H.P., Kinsella, R., \& Duque, G. (2017). Osteosarcopenia: Where bone, muscle, and fat collide. Osteoporosis International, 28(10), 2781-2790.

Honekopp, J., Bartholdt, L., Beier, L., \& Liebert A. (2007). Second to fourth digit length ratio (2D:4D) and adult sex hormone levels: New data and a meta-analytic review. Psychoneuroendocrinology, 32(4), 313-321.

IOM (Institute of Medicine). (2011). Dietary reference intakes for calcium and vitamin D. Washington, DC: National Academies Press.

Jackson, A.S., \& Pollock, M.L. (1978). Generalized equations for predicting body density of men. British Journal of Nutrition, 40(03), 497-504.

Johansson, H., Kanis, J.A., Odén, A., McCloskey, E., Chapurlat, R.D., Christiansen, C., \& Glüer, C.C. (2014). A meta-analysis of the association of fracture risk and body mass index in women. Journal of Bone and Mineral Research, 29(1), 223-233.

Kärkkäinen, M., Rikkonen, T., Kröger, H., Sirola, J., Tuppurainen, M., Salovaara, K., \& Alhava, E. (2008). Association between functional capacity tests and fractures: An eight-year prospective population-based cohort study. Osteoporosis International, 19(8), 1203-1210.

Karsenty, G., Kronenberg, H.M., \& Settembre, C. (2009). Genetic control of bone formation. Annual Review of Cell and Developmental, 25, 629-648.

Khalil, N., Faulkner, K.A., Greenspan, S.L., \& Cauley, J.A. (2014). Associations between bone mineral density, grip strength, and lead body burden in older men. Journal of the American Geriatrics Society, 62(1), 141-146.

Khosla, S., Oursler, M.J., \& Monroe, D.G. (2012). Estrogen and the skeleton. Trends in Endocrinology and Metabolism, 23(11), 576-81.

Klimek, M., Galbarczyk, A., Nenko, I., \& Jasienska, G. (2016). Women with more feminine digit ratio (2D:4D) have higher reproductive success. American Journal of Physical Anthropology, 160(3), 549-553.

Kobayashi, T., \& Kronenberg, H.M. (2014). Overview of skeletal development. In M.J. Hilton (Ed.), Skeletal development and repair: Methods and protocols (pp. 3-12). Totowa, NJ: Humana Press.

Lebrasseur, N.K., Achenbach, S.J., Melton, L.J., Amin, S., \& Khosla, S. (2012). Skeletal muscle mass is associated with bone geometry and microstructure and serum insulin-like growth factor binding protein-2 levels in adult women and men. Journal of Bone and Mineral Research, 27, 2159-2169.

Li, C., Jia, M., Ma, Y., Luo, H., Li, Q., Wang, Y., \& Cao, L. (2016). The relationship between digit ratio and sexual orientation in a Chinese Yunnan Han population. Personality and Individual Differences, 101, 26-29.

Li, X., Gong, X., \& Jiang, W. (2017). Abdominal obesity and risk of hip fracture: A meta-analysis of prospective studies. Osteoporosis International, 28(10), 2747-2757.

Long, F., Chung, U.I., Ohba, S., McMahon, J., Kronenberg, H.M., \& McMahon, A.P. (2004). Ihh signaling is directly required for the osteoblast lineage in the endochondral skeleton. Development, 131, 1309-1318. 
Lu, H., Ma, Z.B., Zhao, J.L., \& Huo, Z.H. (2015). Second to fourth digit ratio (2D:4D) and coronary heart disease. Early Human Development, 91(7), 417-420.

Manning, J.T., Barley, L., Walton, J., Lewis-Jones, D.I., Trivers, R.L., Singh, D., \& Szwed, A. (2000). The 2nd:4th digit ratio, sexual dimorphism, population differences, and reproductive success: Evidence for sexually antagonistic genes?. Evolution and Human Behavior, 21(3), 163-183.

Manning, J.T., Scutt, D., Wilson, J., \& Lewis-Jones, D.I. (1998). The ratio of 2nd to 4th digit length: A predictor of sperm numbers and concentrations of testosterone, luteinizing hormone and oestrogen. Human Reproduction, 13(11), 3000-3004.

Marin, R.V., Pedrosa, M.A.C., Moreira-Pfrimer, L.D.F., Matsudo, S.M.M., \& Lazaretti-Castro, M. (2010). Association between lean mass and handgrip strength with bone mineral density in physically active postmenopausal women. Journal of Clinical Densitometry, 13(1), 96-101.

Miller, L.E., Pierson, L.M., Pierson, M.E., Kiebzak, G.M., Ramp, W.K., Herbert, W.G., \& Cook, J.W. (2009). Age influences anthropometric and fitness-related predictors of bone mineral in men. The Aging Male, 12(2-3), 47-53.

Moon, S.S. (2014). Relationship of lean body mass with bone mass and bone mineral density in the general Korean population. Endocrine, 47(1), 234-243.

Nasri, R., Hassen Zrour, S., \& Rebai, H. (2013). Grip strength is a predictor of bone mineral density among adolescent combat sport athletes. Journal of Clinical Densitometry, 16(1), 92-97.

National Institutes of Health. (2016). Osteoporosis. Retrieved February 2016 from https://www.niams.nih.gov/healthtopics/osteoporosis\#tab-causes.

Pineault, K.M., \& Wellik, D.M. (2014). Hox genes and limb musculoskeletal development. Current Osteoporosis Reports, 12(4), 420-427.

Reid, I.R. (2008). Relationships between fat and bone. Osteoporosis International, 19(5), 595-606.

Saarelainen, J., Kiviniemi, V., Kröger, H., Tuppurainen, M., Niskanen, L., Jurvelin, J., \& Honkanen, R. (2012). Body mass index and bone loss among postmenopausal women: The 10-year follow-up of the OSTPRE cohort. Journal of Bone and Mineral Metabolism, 30(2), 208-216.

Sarkis, K.S., Martini, L.A., Szejnfeld, V.L., \& Pinheiro, M.M. (2012). Low fatness reduced fat intake and adequate plasmatic concentrations of LDL-cholesterol are associated with high bone mineral density in women: A crosssectional study with control group. Lipids in Health and Disease, 11, 37.

Sherk, V.D., Palmer, I.J., Bemben, M.G., \& Bemben, D.A. (2009). Relationships between body composition, muscular strength, and bone mineral density in estrogen-deficient postmenopausal women. Journal of Clinical Densitometry, 12(3), 292-298.

Tagliaferri, C., Wittrant, Y., Davicco, M.J., Walrand, S., \& Coxam, V. (2015). Muscle and bone, two interconnected tissues. Ageing Research Reviews, 21, 55-70.

Trivers, R., Manning, J., \& Jacobson, A. (2006). A longitudinal study of digit ratio (2D:4D) and other finger ratios in Jamaican children. Hormones and Behavior, 49, 150-156.

Wang, L., Huo, Z., Lu, H., Bai, C., Li, K., \& Ma, W. (2018). Digit ratio (2D: 4D) and coronary artery disease in north Chinese women. Early Human Development, 116, 64-67.

WHO. Scientific Group on Prevention, Management of Osteoporosis, \& World Health Organization. (2003). Prevention and management of osteoporosis: Report of a WHO scientific Group World Health Organization. Geneva: WHO.

Xiang, J., Chen, Y., Wang, Y., Su, S., Wang, X., Xie, B., \& Liu, M. (2017). Lean mass and fat mass as mediators of the relationship between physical activity and bone mineral density in postmenopausal women. Journal of Women's Health, 26(5), 461-466.

Yamamoto, T., Tamura, Y., Ono, T., Takei, M., \& Sano, M. (2015). Relationship between digit ratio and idiopathic pulmonary arterial hypertension in Japanese women. Journal of Vascular Medicine and Surgery, 3(1), 1-3.

Zheng, Z., \& Cohn, M.J. (2011). Developmental basis of sexually dimorphic digit ratios. Proceedings of the National Academy of Sciences, 108(39), 16289-16294.

Submitted: April 9, 2018

Accepted: January 28, 2019

Published Online First: November 15, 2019
Correspondence to:

Hamid Arazi

Department of Exercise Physiology

Faculty of Sport Sciences

University of Guilan, Rasht, Iran

P.O. Box: 41635-1438

Phone: 00989111399207

Fax: 00981333690675

E-mail: hamidarazi@yahoo.com

\section{Acknowledgments}

The authors would like to state their appreciation to all the participants who took part in this research.

Conflict of benefits: The authors declare that they have no conflict of interests. 